\title{
PROFESSIONAL RISK, KNOWLEDGE, ATTITUDES AND PRACTICE OF HEALTH CARE PERSONNEL IN SERBIA WITH REGARD TO HIV AND AIDS
}

\author{
Biljana Kocić ${ }^{1}$, Branislav Petrović ${ }^{1}$, Dragan Bogdanović ${ }^{1}$, Jovica Jovanović ${ }^{2}$, Dragana Nikić ${ }^{1}$, Maja Nikolić ${ }^{1}$ \\ ${ }^{1}$ Institute of Public Health, Faculty of Medicine, University of Nišs, Niš, Serbia \\ ${ }^{2}$ Institute of Occupational Health, Faculty of Medicine, University of Niš, Niš, Serbia
}

\begin{abstract}
SUMMARY
The aim of our investigation was to assess HIVIAIDS-related professional risk, knowledge, attitude and practice of health care workers in Niš. A cross-sectional study of health personnel from Primary Health Centre, Clinical Medical Centre and Dental Clinic in Niš was performed. The data were collected by an anonymous questionnaire. Mantel-Haenszel $x^{2}$ testing and multiple logistic regression analysis were applied. Results show that $89 \%$ of health personnel perceived high professional risk of acquiring HIV infection. The risk perception of acquiring HIV infections was higher among those who were frequently exposed to patients' blood and other body fluids ( $O R=10.195 \% \mathrm{Cl}=3.1-32.5)$, and those who had treated HIV-positive patients (OR=3.0 95\% Cl=1.0-8.8). The majority of respondents had insufficient knowledge about the modes of HIV transmission. Nearly two thirds of health personnel agreed that every hospitalized patient should be tested for HIV, and more than four fitths of them agreed that their personal protection was more important than the confidentiality of patient's HIVIAIDS status. Twenty nine percent of health personnel use adequate protection during their daily work with patients. These findings indicated a need for urgent educational and training initiatives of HIV and AIDS for all categories of health care workers.
\end{abstract}

Key words: health care workers, professional risk, HIV infection, attitude, knowledge

Address for correspondence: B. Kocić, Institute of Public Health, Faculty of Medicine, University of Niš, Bul.dr, Z. Đinđića 50, 18000 Niš, R Serbia. E-mail: biljaizzz@yahoo.com

\section{INTRODUCTION}

Health care workers are key players in the prevention and management of blood-borne infection, including human immunodeficiency virus (HIV) $(1,2)$. A number of occupational exposures to the patients' blood and body fluids occur each year in health-care settings $(3,4)$. Workers and employers are urged to take advantage of available engineering controls and work practices to prevent exposure to blood and other body fluids $(1,2)$. A number of studies regarding HIV/AIDS knowledge, attitudes, risk perception and safe practice among health personnel have been conducted $(5,6)$. There is limited literature available on previous studies in Eastern European countries $(7,8)$.

The aim of this study was to assess HIV/AIDS-related perception of professional risk, knowledge, attitude and practice of health care workers in Niš.

\section{MATERIALS AND METHODS}

A total of 230 health care workers in Niš were included in the study, which represents $5 \%$ of the total number $(4,544)$ of health care personnel in Niš. Allowed withdrawal of subjects was five percentage. According to the data of Statistical Annual for 2000, there were $36.7 \%$ of health care personnel in primary health care in Niš (Primary Health Centre) and 63.3\% in secondary and tertiary health care in Niš (Clinical Medical Centre and Dental Clinic). According to the same data, the ratio of the group of doctors and dentists, and the group of nurses and laboratory technicians was 1:3. The respondents were selected through two-stage stratified sampling. In the first phase health care workers were divided into two strata: 1 . subjects in primary health care, and 2. professionals in secondary and tertiary health care. In the second step, both strata included two groups: 1 . doctors and dentists and 2. nurses and laboratory technicians. The health care workers in primary health care were from: general practice, occupational medicine, gynecology, dentistry and laboratory. Health care workers in secondary and tertiary health care were from: gynecology and obstetrics, laboratory, infectious diseases, pneumophtisiology, gastroenterology, hematology, nephrology, urology, alergology and immunology, otorhinolaryngology, surgery (general, orthopedic and traumatology, vascular, maxillofacial), emergency medicine, dermatology, forensic medicine and dentistry. The ratio of the group of doctors and dentists, and the group of nurses and laboratory technicians, as well as the ratio of the group of primary care employees, and the group of secondary and tertiary health 
employees was preserved in the sample. Distribution of health care workers according to departments in selected health care institutions are in accordance with distribution of subjects included in the sample of primary care, and in the sample of secondary and tertiary health care. Using random sample method, subjects from different departments were selected.

The data were collected by an anonymous questionnaire containing 36 questions and distributed by trained interviewers. Questions covered demographic characteristics, risk perception and prevention, daily professional activities and practices, knowledge, attitudes and education of health care personnel regarding HIV and AIDS. A multi-disciplinary team consisting of epidemiologists, public health practitioners, biostatisticians and health care workers designed the questionnaire which was pre-tested among health care workers.

The Mantel-Haenszel $\chi^{2}$ test was applied for assessing the significance of differences by occupation and perception of risk for acquiring HIV infection. A multiple logistic regression was performed in order to calculate the independent odds ratio (OR) of the risk perception for acquiring HIV infection and the corresponding 95\% confidence intervals (CI). The probability $\mathrm{p}<0.05$ was taken as the minimum level of significance.

Data were analyzed with SPSS software package (version 10.0, SPSS Inc., Chicago, IL, USA).

\section{RESULTS}

Questionnaires were completed by 222 (96.5\%) health care workers. The sample consisted of 185 (83\%) female and 37 (17\%) male. A sample included a total of 148 (67\%) nurses, 50 (23\%) doctors, 9 (4\%) dentists and 15 (6\%) laboratory technicians. The mean age of the respondents was $40.6 \pm 9.3$ years. Duration of employment in the current job was $13.4 \pm 10$ years. Among the health care workers we studied, 61 (27\%) were practicing surgery and 194 (87.4\%) carried out some form of intervention with a risk of HIV infection (contact with blood or other body fluids). A total of 198 subjects (89\%) perceived high professional risk of acquiring HIV infection.

Respondents had deficient knowledge about the modes of HIV transmission. The majority of true answers were found relating to HIV transmission by blood, sperm/vaginal secretions, and sweat. The majority of false answers were found relating to HIV transmission by saliva/tears, urine, and feces. The group of doctors and dentists didn't have generally better knowledge than the other group of nurses and laboratory technicians (Table 1).

Within the last year, 128 respondents (57.6\%) had skin contact with patient's blood, 111 (50\%) reported needlestick injuries, 80 (36\%) mentioned cuts from sharp instruments and 76 (34.2\%) reported contact of eye and other mucosa with patient's blood.

Table 1. HIVIAIDS-related knowledge, attitudes and practice of health personnel

\begin{tabular}{|c|c|c|c|c|c|}
\hline & $\begin{array}{c}\text { Doctors / Den- } \\
\text { tists } \\
\mathrm{n}(\%) \\
\end{array}$ & $\begin{array}{c}\text { Nurses / Labora- } \\
\text { tory technicians } \\
\mathrm{n}(\%)\end{array}$ & $\begin{array}{l}\text { Total } \\
\text { n (\%) }\end{array}$ & $x^{2}$ & $\mathrm{p}$ \\
\hline \multicolumn{6}{|l|}{ Corect answers about the modes of HIV transmission } \\
\hline Blood & $58(98.3)$ & $159(97.5)$ & $217(94.6)$ & 0.03 & 0.861 \\
\hline Sperm/vaginal secretions & $41(69.5)$ & $103(53.2)$ & $144(64.9)$ & 0.57 & 0.386 \\
\hline Saliva/tears & $16(27.1)$ & $61(37.4)$ & $77(34.7)$ & 2.02 & 0.155 \\
\hline Sweat & $28(47.5)$ & $89(54.6)$ & $117(52.7)$ & 0.88 & 0.346 \\
\hline Faeces & $21(35.6)$ & $74(45.4)$ & $95(42.8)$ & 1.69 & 0.193 \\
\hline Urine & $20(33.9)$ & $71(43.6)$ & $91(41.0)$ & 1.66 & 0.197 \\
\hline \multicolumn{6}{|l|}{ Type of exposure } \\
\hline Skin contact & $27(45.8)$ & $101(62.0)$ & $128(57.6)$ & 4.64 & 0.031 \\
\hline Needlesticks & $21(35.6)$ & $90(55.2)$ & $111(50.0)$ & 6.64 & 0.009 \\
\hline Cuts from sharp instruments & $12(20.3)$ & $68(41.7)$ & $80(36.0)$ & 8.55 & 0.003 \\
\hline Contact of eye and other mucosa & $22(37.3)$ & $54(33.1)$ & $76(34.2)$ & 0.33 & 0.564 \\
\hline \multicolumn{6}{|l|}{ Attitudes (Statement: I agree) } \\
\hline Every hospitalized patient should be tested for HIV & $42(73.5)$ & $122(74.8)$ & $164(73.9)$ & 0.30 & 0.584 \\
\hline $\begin{array}{l}\text { To protect HCWs is more important than } \\
\text { con dentiality of patient's HIV status }\end{array}$ & $48(81.3)$ & $139(85.3)$ & $187(84.2)$ & 0.50 & 0.479 \\
\hline $\begin{array}{l}\text { HCWs should be able to refuse to care for } \\
\text { an HIVIAIDS patient }\end{array}$ & $5(8.5)$ & $18(11.0)$ & $23(10.4)$ & 0.31 & 0.579 \\
\hline HIV positive HCWs should not practice & $16(27.1)$ & $80(49.1)$ & $96(43.2)$ & 8.47 & 0.003 \\
\hline HIV positive status is the individual's own fault & $6(10.2)$ & $16(9.8)$ & $22(9.9)$ & 0.01 & 0.938 \\
\hline $\begin{array}{l}\text { Using appropriate barriers when working } \\
\text { with every patient }\end{array}$ & $19(32.2)$ & $46(28.2)$ & $65(29.3)$ & 0.33 & 0.565 \\
\hline $\begin{array}{l}{ }^{*} \text { Additional protection if HIV status of patient } \\
\text { is known }\end{array}$ & $22(66.7)$ & $111(89.5)$ & $133(84.7)$ & 10.44 & 0.001 \\
\hline HIV testing & $23(39.0)$ & $59(36.2)$ & $8236.9)$ & 0.14 & 0.704 \\
\hline
\end{tabular}

* Total of 157 repondents 
Skin contact with patient's blood $\left(\chi^{2}=4.6 ; \mathrm{p}=0.031\right)$, needlestick injuries $\left(\chi^{2}=6.6 ; \mathrm{p}=0.009\right)$ and the cuts from sharps $\left(\chi^{2}=8.5\right.$; $\mathrm{p}=0.003$ ) occurred most frequently in the group of nurses and laboratory technicians (Table 1).

Among the health care professionals we studied, 164 (74\%) agreed that all inpatients should be tested for HIV. The majority of health care workers (84.2\%) agreed that their personal protection was more important than the confidentiality of patient's HIV/AIDS status. Twenty-three subjects (10\%) agreed that health care workers should be offered the option to be excused from care for an HIV/AIDS patient and 22 professionals (9.9\%) thought that HIV-positive status was the individual's own fault. Ninety-six subjects (43\%) agreed with restricting HIV-positive health care workers from practicing medicine. Nurses and laboratory technicians agreed with this statement more frequently than doctors and dentists $\left(\chi^{2}=8.5 ; \mathrm{p}=0.003\right)$ (Table 1$)$.

Sixty-five respondents (29\%) protected themselves regularly, using appropriate barriers (gloves, glasses and mask). There was no significant difference between the groups $\left(\chi^{2}=0.3\right.$; $\left.p=0.565\right)$ (Table 1). If the HIV status of a patient was known, 133 respondents (85\%) would use additional protection. Nurses and laboratory technicians used additional personal protection more frequently than doctors and dentists $\left(\chi^{2}=10.4 ; \mathrm{p}=0.001\right)$ (Table 1 ).

Most participants, 193 (87\%) had not been informed about guidelines for protection against HIV, and protocols of post exposition prophylaxis or such protocols did not exist at their workplaces.

Twenty-five professionals (11\%) received education about HIV and AIDS in the last year and 81 (36.5\%) within the last five years. There was no significant difference between the groups in education about HIV and AIDS. The majority of medical personnel (77\%) expressed a need to be further educated about HIV and AIDS. Thirty-seven per cent of respondents had previously been tested for HIV status, with no significant difference between the groups $\left(\chi^{2}=0.14 ; \mathrm{p}=0.704\right)$ (Table 1$)$.

Using logistic regression, we found that perception of professional risk of acquiring HIV infections was associated with everyday practice and was higher among health care workers who were exposed to patients blood and other body fluids, and those who had previously treated HIV-positive patients (Table 2).

\section{DISCUSSION}

Our study revealed gaps in the knowledge of health care workers about HIV infection. We found that medical personnel in Niš had deficient knowledge about the modes of HIV transmission. Very different to what was expected, doctors and dentists didn't have generally better knowledge than nurses, laboratory technicians and other medical staff. Insufficient professional education regarding HIV and AIDS has been previously reported (7-12). Gaps in the knowledge could be explained by different factors including a very long period of dramatic and disturbing socioeconomic crisis in Serbia.

The results of a number of studies $(9,10,13)$, suggested that a high proportion of health care workers believed that they were at risk of acquiring HIV infection through occupational exposure, which is very similar to our findings.

Our data regarding high perception of professional risk of acquiring HIV infections among health care workers who were exposed to patients blood and other body fluids, and those who had previously treated HIV-positive patients, are in accordance with results from other studies $(14,15)$. It is worrying to note that $71 \%$ of health care workers in Niš did not use adequate protection (such as gloves, protection glasses or a mask) in all medical procedures with patients. Our findings are in correlation with results from other studies indicating that there was poor adherence to universal precautions $(16,17)$. This could be explaned by the finding that $87 \%$ of the respondents had not been informed about guidelines for protection against HIV, and protocols of post exposure prophylaxis or such protocols did not exist at their workplaces. Additionally, unsafe practice could be exacerbated by different factors including hospital overcrowding and inadequate supplies of basic safety equipment $(10,17)$. Moreover, a long period of socio-economic crisis in Serbia should be taken into account. In order to do their jobs safely and effectively, health professionals must be provided with adequate supplies of essential protective materials.

Our data regarding the most common types of exposure (a skin contact with patient's blood, needlestick injuries and cuts from sharp instruments) are in accordance with other relevant reports $(7,16)$. Similarly, our findings correlate with results from other

Table 2. Perception of HIVIAIDS risk of health personnel-multiple logistic regression analysis

\begin{tabular}{|c|c|c|c|c|c|}
\hline \multirow[t]{2}{*}{ Variable } & \multicolumn{2}{|c|}{ Risk perception } & \multirow[t]{2}{*}{ OR } & \multirow[t]{2}{*}{$95 \% \mathrm{Cl}$} & \multirow[t]{2}{*}{$\mathrm{p}$} \\
\hline & No & Yes & & & \\
\hline Daily professional work activities in ambulance & $161(72.5)$ & $61(27.5)$ & 1.4 & $0.3-6.9$ & 0.707 \\
\hline Exposure to blood and other body uids & $28(12.6)$ & $194(87.4)$ & 10.1 & $3.1-32.5$ & 0.000 \\
\hline Cut from sharp instrument in the last year & $142(64.0)$ & $80(36.0)$ & 0.8 & $0.2-3.0$ & 0.734 \\
\hline Skin contact with patient's blood in the last year & $94(42.3)$ & $128(57.7)$ & 1.3 & $0.4-4.1$ & 0.639 \\
\hline $\begin{array}{l}\text { Contact of eye or other mucosa with patient's blood } \\
\text { in the last year }\end{array}$ & $146(65.8)$ & $76(34.2)$ & 2.8 & $0.5-15.2$ & 0.238 \\
\hline Previously treated HIV positive patients & $95(42.8)$ & $127(57.2)$ & 3.0 & $1.0-8.8$ & 0.045 \\
\hline $\begin{array}{l}{ }^{*} \text { To protect HCWs is more important than } \\
\text { con dentiality of patient's HIV status }\end{array}$ & $187(84.2)$ & $22(9.9)$ & 0.8 & $0.1-4.1$ & 0.739 \\
\hline
\end{tabular}

- 13 respondents had no opinion 
studies $(3,10,18)$ indicating that needlestick injuries and the cuts from sharps occurred most frequently in nurses and laboratory technicians than in doctors and dentists.

The results of a number of studies $(9,11,13,15)$ suggested that a significant proportion of health-care professionals agreed that every hospitalized patient should be tested for HIV, and most of them agreed that their personal protection was more important than the confidentiality of patient's HIV/AIDS status, which is very similar to our findings. Deficiencies of knowledge with regard to HIV may contribute to negative, discriminatory attitudes toward infected individuals and reduce compliance with infection control recommendations $(10,12,13,15,17)$.

When interpreting the findings of this study, a number of limitations should be considered. The cross-sectional study design did not allow us to establish causal relationships among variables. Retrospective reporting of occupational exposures is subject to recall bias. Respondents were asked about the number of incidents which had occurred in the last year. Data of the study are based on self-reports and perceptions of health personnel which can be time changeable.

It is very important to note that such findings represent the risk perception, knowledge, attitudes and practice of health personnel in Niš during a period of dramatic and disrupting socio-economic and political changes in Serbia. Inadequate education about HIV/ AIDS and a lack of protective materials appear to contribute these attitudes and practices.

An important strength of the study was the very high response rate. This could be explained by the fact that the data were gathered through anonymous questionnaire distributed by trained interviewers with active participation in collecting data.

In conclusion, the results indicated a need for educational initiatives of HIV and AIDS for medical staff. This study revealed that well-coordinated continuing education of HIV/AIDS for all categories of health care workers in Niš is recommended as a vital strategy in the crusade against HIV. Training on risk management and individual responsibilities regarding safety can improve the present situation of infection control. Employers should provide written protocols of post exposure prophylaxis. All health care workers have been informed about different guidelines for safety measures and protocols of post exposure prophylaxis. The study also suggests that health professionals must be provided with adequate supplies of essential protective materials.

\section{REFERENCES}

1. Twitchell KT. Bloodborne pathogens. What you need to know-Part I. AAOHN J. 2003 Jan;51(1):38-45.

2. Twitchell KT. Bloodborne pathogens. What you need to know-Part II. AAOHN J. 2003 Feb;51(2):89-97.

3. Dement JM, Epling C, Ostbye T, Pompeii LA, Hunt DL. Blood and body fluid exposure risks among health care workers: results from the Duke Health and Safety Surveilance System. Am J Ind Med. 2004 Dec;46(6):637-48.

4. U.S. Public Health Service. Updated U.S. Public Health Service Guidelines for the Management of Occupational Exposures to HBV, HCV and HIV and Recommendations for Postexposure Prophylaxis. MMWR Recomm Rep. 2001 Jun 29;50(RR-11):1-52.

5. Kermode M. Unsafe injections in low-income country health settings: need for injection safety promotion to prevent the spread of blood-borne viruses. Health Promot Int. 2004 Mar;19(1):95-103.

6. Massiah E, Roach TC, Jacobs C, St John AM, Inniss V, Walcott J, et al Stigma, discrimination, and HIV/AIDS knowledge among physicians in Barbados. Rev Panam Salud Publica. 2004 Dec;16(6):395-401.

7. Žakula N, Garotić-Ilić L, Rakić M. Attitudes and knowledge about HIV infection and transmission risk in medical institutions among HCWs. In: Proceedings of the 9th Meeting of Serbian HCWs; 1998 Jun 20-24; Tara, Serbia. Belgrade: Serbian Medical Association; 1998. (In Serbian.)

8. Žakula N, Radivojević J. Healthcare personel and HIV prevention. In: Proceedings of the Scientific Meeting "Medical and social aspects of HIV infection and AIDS”; 2004 Apr 23; Belgrade, Serbia. Belgrade: Serbian Academy of Sciences and Arts; 2004. (In Serbian.)

9. Hesse J, Adu-Aryee N, Entsua-Mensah K, Wu L. Knowledge, attitude and practice universal basic precautions by medical personnel in a teaching hospital. Ghana Med J. 2006 Jun;40(2):61-4.

10. Hentgen V, Jaureguiberry S, Ramiliarisoa A, Andrianantoandro V, Belec M. Knowledge, attitude and practices of health personnel with regard to HIV/AIDS in Tamatave (Madagascar). Bull Soc Pathol Exot. 2002 Jun;95(2):103-8. (In French.)

11. Scoular A, Watt AD, Watson M, Kelly B. Knowledge and attitudes of hospital staff to occupational exposure to bloodborne viruses. Commun Dis Public Health. 2000 Dec;3(4):247-9.

12. Sadob AE, Fawole AO, Sadoh WE, Oladimeji AO, Sotiloye OS. Attitude of health-care workers to HIV/AIDS. Afr J Reprod Health. 2006 Apr;10(1):39-46.

13. Maupomé G, Acosta-Gío E, Borges-Yáñez SA, Díez-de-Bonilla FJ. Survey on attitudes toward HIV-infected individuals and infection control practices among dentists in Mexico City. Am J Infect Control. 2000 Feb;28(1):21-4.

14. Hossini CH, Tripodi D, Rahhali AE, Bichara M, Betito D, Curtes JP, et al. Knowledge and attitudes of health care professionals with respect to AIDS and the risk of occupational transmission of HIV in 2 Moroccan hospitals. Sante. 2000 Sep-Oct;10(5):315-21. (In French.)

15. Reis C, Heisler M, Amowitz LL, Moreland RS, Mafeni JO, Anyamele $\mathrm{C}$, et al. Discriminatory attitudes and practices by health workers toward patients with HIV/AIDS in Nigeria. PLoS Med. 2005 Aug;2(8):e246.

16. Gurubacharya DL, Mathura KC, Karki DB. Knowledge, attitude and practices among health care workers on needle-stick injuries. Kathmandu Univ Med J. 2003 Apr-Jun;1(2):91-4.

17. Aisien AO, Shobowale MO. Health care workers' knowledge on HIV and AIDS: universal precautions and attitude towards PLWHA in Benin-City, Nigeria. Niger J Clin Pract. 2005 Dec;8(2):74-82.

18. Smith DR, Leggat PA, Takahashi K. Percutaneous exposure incidents among Australian hospital staff. Int J Occup Saf Ergon. 2005;11(3):32330 . 